\title{
Performance investigation of patch and bow-tie antennas for ground penetrating radar applications
}

\author{
Nairit Barkataki ${ }^{*}$, Banty Tiru ${ }^{2}$ and Utpal Sarma ${ }^{3}$ \\ Assistant Professor, Department of Instrumentation \& USIC, Gauhati University, Guwahati, India ${ }^{1}$ \\ Associate Professor, Department of Physics, Gauhati University, Guwahati, India ${ }^{2}$ \\ Professor, Department of Instrumentation \& USIC, Gauhati University, Guwahati, India ${ }^{3}$
}

Received: 09-April-2021; Revised: 20-June-2021; Accepted: 23-June-2021

(C)2021 Nairit Barkataki et al. This is an open access article distributed under the Creative Commons Attribution (CC BY) License, which permits unrestricted use, distribution, and reproduction in any medium, provided the original work is properly cited.

\begin{abstract}
Ground Penetrating Radar (GPR) uses electromagnetic waves to detect objects beneath the earth's surface. Even though signal processing plays a significant role in GPR performance, the quality of the acquired data is also dependant on the antenna and the associated electronic circuitry. Bow-tie antennas are a popular choice in GPR systems because of their lightweight design, planar structure and ultra-wideband characteristics. Recent advances in planar microstrip antenna design have thrown up lots of possibilities for this antenna type in GPR applications. In this paper, a comparative analysis of a planar microstrip antenna and a bow-tie slot antenna is presented. Both the antennas are designed for a centre frequency of $1.5 \mathrm{GHz}$, and are fabricated on Flame Retardant 4 (FR4) substrate. The planar microstrip antenna is fed by a microstrip line, whereas the co-planar waveguide feeding is used for the bow-tie antenna. The bow-tie antenna exhibits a measured bandwidth of $\sim 65 \%$, with minimum return loss of $-33.60 \mathrm{~dB}$ at $1.46 \mathrm{GHz}$. On the other hand, the microstrip antenna exhibits a return loss of $-30.53 \mathrm{~dB}$ at its centre frequency of $1.51 \mathrm{GHz}$.
\end{abstract}

Keywords

Patch, Bow-tie, Slot, Antenna, Ground penetrating radar.

\section{Introduction}

Ground penetrating radar (GPR) detects objects beneath the surface of the earth. It is also used in applications such as the characterisation of mortar cracks [1], soil surveys [2], diagnosis of pavement structures [3], bedrock identifications [4], detection of cavities in fragile regions [5], etc. Tree root biomass investigation is also done using GPR. This helps in aeration through root channels, water infiltration and soil amelioration [6]. In short, GPR has proven a useful tool in various fields of engineering, archaeology, geophysics and so on [7].

The choice of the antenna greatly affects the efficiency of a GPR system. These antennas have to be custom designed, considering the fact that the system is operating close to the ground. The designers have to take into account various characteristics such as propagation path, dielectric properties of the subsurface, frequency and the bandwidth of the signal.

\footnotetext{
*Author for correspondence

This work was supported by MeitY (Govt. of India) under Visvesvaraya PhD Scheme

753
}

The penetration depth of the signal depends on the operational frequency while the resolution of the system depends on the bandwidth of the signal.

The propagation media are usually lossy and heterogeneous in nature. Moreover, better resolution demands the use of higher frequency. A GPR system cannot achieve larger penetration depth (low frequency) and better resolution (high frequency) at the same time. Moreover, eliminating the effects of the propagation media on the higher frequencies of the antenna is also a challenge. Therefore, designers have to make a compromise between the penetration depth and the resolution while modelling the antennas.

\section{Literature review}

The antenna of a GPR system needs to have high gain, low form factor, Ultra-Wideband (UWB) characteristics and so on [8]. As such, the types of antennas which can meet such requirements are limited to dipole antenna $[9,10]$, Vivaldi antenna [11, 12], Transverse Electromagnetic (TEM) horn antenna $[8,11,13,14]$, bow-tie antenna $[10,11][15-17]$, planar spiral antenna $[8,11]$, and so on. 
Lu et al. [18] designed a Very High Frequency (VHF) band UWB monopole antenna, which was part of the Chinese Mars rover Zhurong. The rover landed on Mars on 14 May 2021. The overall length of the antenna was $\sim 1 / 8$ times the lowest operating frequency. However, with an operation band of 30-90 $\mathrm{MHz}$, the length of the antenna was $1.35 \mathrm{~m}$.

\subsection{Planar antenna}

Planar antenna with microstrip or co-planar waveguide feeding is a suitable option for integration with Printed Circuit Board (PCB) circuitry. In recent times, patch antenna [19-21] is gaining popularity in GPR applications, given its low profile, lightweight, inexpensive and UWB characteristics.

Many designs, including UWB square planar antenna [22], half-disk antenna [23] and planar horn antenna [24] have focussed on planar antennas.

Several rectangular patch antenna designs have been reported in various literature. They have various configurations such as circular, elliptical, square, pentagonal, hexagonal, and so on, which enhance their UWB characteristics [21,25,26]. Half-square [27], semi-circular [28] and half-hexagonal [29] monopole designs have also been reported for UWB applications. Studies by Ling et al. and Thomas et al. have demonstrated simple printed patch antennas with quasi-transmission lines and band dispensation [30,31].

Numerous designs of spiral antennas for GPR applications can be found in existing literature. Richardson et al.[32] presented the design of a cavity backed UWB spiral antenna, which had an operating frequency of $0.75-1.25 \mathrm{GHz}$ with a peak gain of $6 \mathrm{~dB}$. A fully planar Archimedean spiral antenna design was proposed recently by Bousbaa et al., which had an integrated planar balun [33]. The proposed antenna had physical dimensions of $90 \mathrm{~mm} \times 90 \mathrm{~mm}$ for an operating range of $2.14-9.8 \mathrm{GHz}$. However, the presence of a significant ringing effect and the need of a balun has limited the applications of spiral antennas.

Guo et al. [34] demonstrated the design of a UWB Vivaldi antenna which was to be used in a GPR system. It was designed to have exponential tapered slots and demonstrated a wide operating band from 0.3 - $2 \mathrm{GHz}$ with gains of 4.4-11.5 dBi. In spite of its very good performance, its size $450 \mathrm{~mm} \times 600 \mathrm{~mm}$ was too large to be fabricated using the commonly available Flame Retardant 4 (FR4) boards, which come in sizes of $300 \mathrm{~mm} \times 300 \mathrm{~mm}$.
Cheng et al.[12] presented another design of a compact vivaldi antenna for GPR systems. It was loaded with artificial materials with gains of 1-2 dB. Others have reported using Vivaldi elements in the metastatic antenna array design[35], planar slotted patch antenna [36] and a printed circular UWB antenna[37] for GPR applications.

Bow-tie antennas have become a preferred choice for GPR applications and a wide variety of designs have been proposed over the years [17, 38, 39]. Major GPR manufacturers like GSSI, GeoRadar, MALA and others use bow-tie antennas in their flagship products.

Takizawa et al. [40] presented a folded bow-tie antenna having UWB characteristics. A cavity backed bow-tie antenna was proposed by Liu et al. [41].

A dielectric loading was used to improve its performance. The antenna had an operating frequency range of $1-4 \mathrm{GHz}$ and a $5-9 \mathrm{dBi}$ boresight gain. A slotted bow-tie antenna design was presented by $\mathrm{Li}$ and Chen [42] in which the antenna was loaded with an artificial magnetic conductor. It had an operating range of $0.56-1.18 \mathrm{GHz}$. Modifications based on bow-tie antennas are also studied nowadays.

Chen et al.[43] recently presented a tripod-shaped UWB antenna, which was based on bow-tie antenna. The antenna's bandwidth was $0.75-1.85 \mathrm{GHz}$; and the simulation results showed good UWB characteristics.

\subsection{Feeding mechanisms}

Various feeding mechanisms such as Microstrip Line (MPL), Coplanar Waveguide Line (CPW), coplanar parallel stripline, double sided parallel strip line etc. can be used to feed a planar antenna [44]. Among these, MPL and CPW are the most popular ones.

Garg et al. [45] extensively studied the design and analysis of feeding techniques for microstrip lines. However, MPL has certain inherent disadvantages such as narrow bandwidth and inability to feed balanced antennas like bow-tie, planar spiral etc. The cross sectional view of an MPL is shown in Figure 1. Planar monopole antennas are generally fed with MPL as presented in $[21,28,46]$.

CPW is preferred for feeding antennas, which have balanced output as well as various other advantages such as ease of fabrication, control over impedance characteristics etc. [47]. The cross section of a coplanar waveguide is shown in Figure 2. Wideband and balanced planar antennas are generally fed with 
CPW $[48,49]$ as it retains or enhances the wideband characteristics of the antennas and also helps in impedance matching. For antennas used in GPR applications, ungrounded CPW is generally used as the antenna side facing the earth's surface does not have any ground plane.

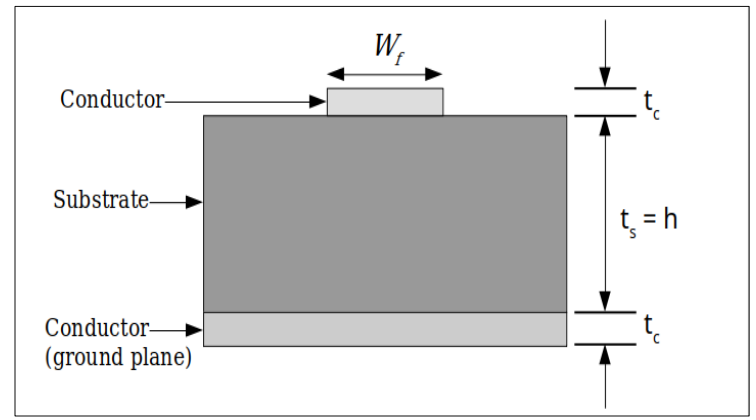

Figure 1 Cross section of MPL

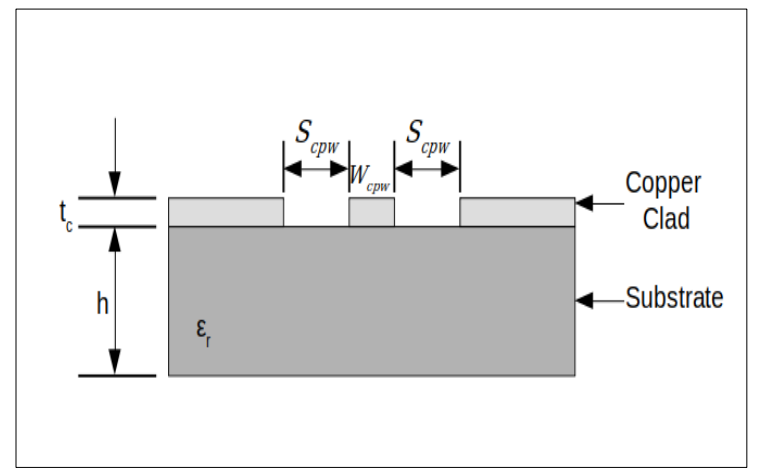

Figure 2 Cross section of CPW

Most of the antenna types discussed above have wide bandwidths and simple structures. However, most of them are not suitable for fabrication using PCBs as they do not have planar structures. Even if they have a planar structure, the problem of feeding and impedance matching arises since they cannot be printed on the same PCB as the one having associated electronics. Moreover, the use of artificial materials as reflectors and loading elements complicates the design process for such antennas.

In this paper, a comparative analysis of a planar microstrip antenna and a bow-tie slot antenna is presented. Both antennas are designed and simulated for a central frequency of $1.5 \mathrm{GHz}$ and are fabricated on an FR4 substrate. The planar microstrip antenna is fed with a $50 \Omega$ MPL, whereas co-planar waveguide feeding is used for the bow-tie antenna. The design parameters are optimised by multiple simulation runs. The antennas have been designed for best possible performance characteristics without using artificial materials for loading purposes. The antennas are fabricated on commonly available FR4 substrates and return loss measurements are obtained using a Vector Network Analyser (VNA).

\section{Methods}

\subsection{Planar microstrip patch antenna}

A patch antenna consists of a patch which radiates and ground plane (full or partial). The partial ground plane can have a defected ground structure [50]. The difference between electrical and physical size depends on fringing effect as well as the thickness and permittivity of the substrate.

The patch length is critical in the design of the antenna as it determines the resonant frequency. The patch length $\mathrm{L}$ and width $\mathrm{W}$ for a rectangular patch antenna is shown by Equation 1 and 2 [45] as:

$$
\begin{aligned}
& L=\frac{c}{2 f_{r} \sqrt{\epsilon_{r}}} \\
& W=\frac{c}{2 f_{r} \sqrt{\frac{\left(\epsilon_{r}+1\right)}{2}}}
\end{aligned}
$$

where, $c$ is the velocity of light, $f_{r}$ is the frequency of resonance and $\epsilon_{r}$ is the relative permittivity of the substrate.

The feeding point of a patch antenna is typically located somewhere along the resonant length in the centre of the patch width. Observing the variations in the magnetic and electric fields, it is found that the impedance is $\sim 50 \Omega$ somewhere along the resonant length of the patch, around $12.5 \mathrm{~mm}$ from the edge. This is the feeding point of the antenna. A microstrip line at the edge of the patch is used to feed it. The advantage of using MPL is the ability to place circuitry on the same PCB.

The impedance near the edge of the patch is quite high. This is solved by creating an inset for the microstrip line to the $50 \Omega$ impedance point.

From equations 1 and 2, the dimensions of the patch are calculated, considering $f_{r}=1.5 \mathrm{Ghz}$ and $\mathrm{c}=3 \times 10^{8}$ $\mathrm{m} / \mathrm{s}$.

The antenna's geometry is shown in Figure 3. An FR4 substrate with copper on both sides is considered. The patch is fed by a MPL of $2.8 \mathrm{~mm}$ width. The thickness of copper clad is $t_{c}=0.035 \mathrm{~mm}(1.4$ mils $)$. The ground plane covers the entire area on the other side of the substrate. The dimensions are further optimised through several simulation runs in CST Microwave Studio (Name of the software) to get the values as given in Table 1. 
Nairit Barkataki et al.

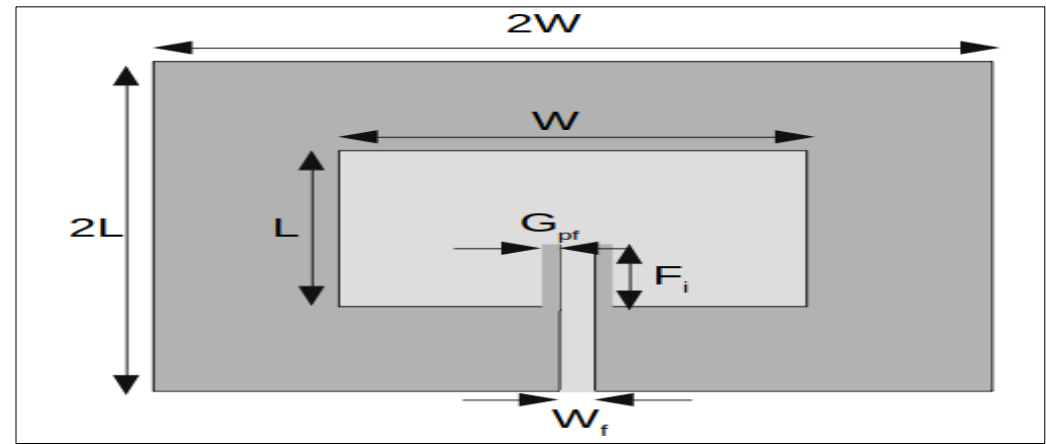

Figure 3 Geometry of the microstrip antenna

Table 1 Optimised parameters for MPL fed patch antenna design

\begin{tabular}{lcc}
\hline Parameters & Symbols & Values \\
\hline Patch length & $\mathrm{L}$ & $45.65 \mathrm{~mm}$ \\
Patch width & $\mathrm{W}$ & $61.43 \mathrm{~mm}$ \\
Length of the feed line & $L_{f}$ & $36.61 \mathrm{~mm}$ \\
Width of the feed line & $W_{f}$ & $2.8 \mathrm{~mm}$ \\
Height of the substrate, FR4 & $\mathrm{h}$ & $1.6 \mathrm{~mm}$ \\
Height of the conductor, Cu layer & ${ }_{t}$ & $0.035 \mathrm{~mm}$ \\
Dielectric constant of the substrate & ${ }_{c}$ & 4.3 \\
Feed line inset length & ${ }_{r}$ & $12.5 \mathrm{~mm}$ \\
Gap between feed line and patch & $G_{p f}$ & $1 \mathrm{~mm}$ \\
\hline
\end{tabular}

\subsection{CPW-fed Bow-tie slot antenna}

The characteristics of a bow-tie antenna are mainly specified by angles and therefore, it is considered as a frequency-independent antenna. Three parameters primarily determine its geometry, as shown in Figure 4 [15].
- flare angle $\boldsymbol{\theta}_{\boldsymbol{f}}$ affects the bandwidth

- gap $\mathbf{g}$ between the arms influences the antenna performance

- length a of the armaffects radiation efficiency

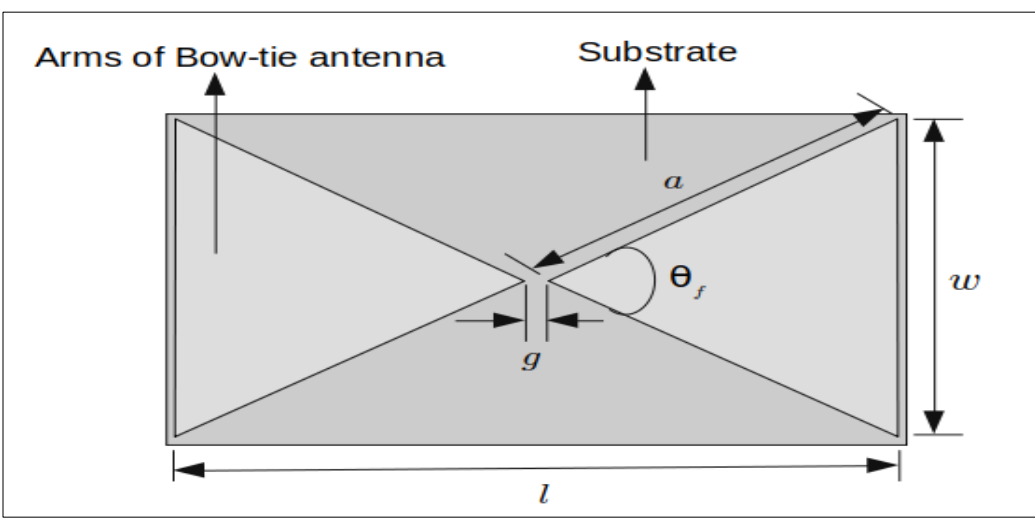

Figure 4 Geometry of the bow-tie antenna

The relation between characteristic impedance and flaring angle is shown by Equation 3 [38].

$Z_{c}=120 \ln \left(\cot \left(\frac{\Theta_{f}}{4}\right) a\right)$

where $\boldsymbol{\theta}_{\boldsymbol{f}}$ is the flaring angle. The length $l$ for a wavelength $\lambda_{0}$ is shown by Equation 4 [39].

$$
l=\lambda_{0} \times\left(\frac{1}{\sqrt{\epsilon_{e f f}}}\right)
$$

The effective relative permittivity for an antenna of width $w$ and substrate thickness $h$ can be calculated using Equation 5 [38]. 
$\epsilon_{e f f}=\left(\frac{\epsilon_{r}+1}{2}\right)+\left(\epsilon_{r}-1\right)\left(1+\left(10 \frac{h}{w}\right)\right)^{-0.5555}$

Where both $w$ and $h$ are in $\mathrm{mm}$. The resonant frequency $\left(f_{r}\right)$ of the different modes of the antenna is shown by Equation 6 [38].

$f_{r}=c \frac{K_{m n}}{2 \pi \sqrt{\epsilon_{r}}}$

where $K_{m n}$ is the resonating mode.

A slot type structure is chosen for the bow-tie as its radiation pattern can be controlled more easily. The characteristic impedance $Z_{0}$, of the coplanar waveguide is calculated by the Equations 7, 8, 9, 10 and 11 [51].

$Z_{0}=\left(\frac{30 \times \pi}{\sqrt{\epsilon_{e f f}}}\right)\left(\frac{K\left(k^{\prime}\right)}{K(k)}\right)$

where

$\epsilon_{\text {eff }}=1+\left\{\frac{\left(\epsilon_{r}-1\right)}{2}\right\}\left\{\left(\frac{K\left(k^{\prime}\right)}{K(k)}\right)\left(\frac{K\left(k_{1}\right)}{K\left(k_{1}^{\prime}\right)}\right)\right\}$

$k=\frac{w_{c p w}}{w_{c p w}+2 S_{c p w}}$ $k_{1}=\frac{\sinh \left(\frac{\pi w_{c p w}}{4 h}\right)}{\sinh \left(\frac{\left(w_{c p w}+2 S_{c p w}\right) \pi}{4 h}\right)}$

$k^{\prime}=\sqrt{\left(1+k^{2}\right)}$

Here, $k$ denotes complete elliptic integral of the first kind, $w_{c p w}$ is the width of the CPW feed, and $S_{c p w}$ is the width of the space between the CPW, as shown in Figure 2.

By using the Equation 3 to Equation 11, the design parameters for the bow-tie antenna are calculated.

The design of the bow-tie antenna is shown in Figure 5. The antenna is designed on a single sided copperclad FR4 substrate and fed by a CPW line. The thickness of copper clad is $t_{c}=0.035 \mathrm{~mm}$ ( 1.4 mils). The dimensions are further optimised through several simulation runs in CST Microwave Studio to get the final values shown in Table 2 .

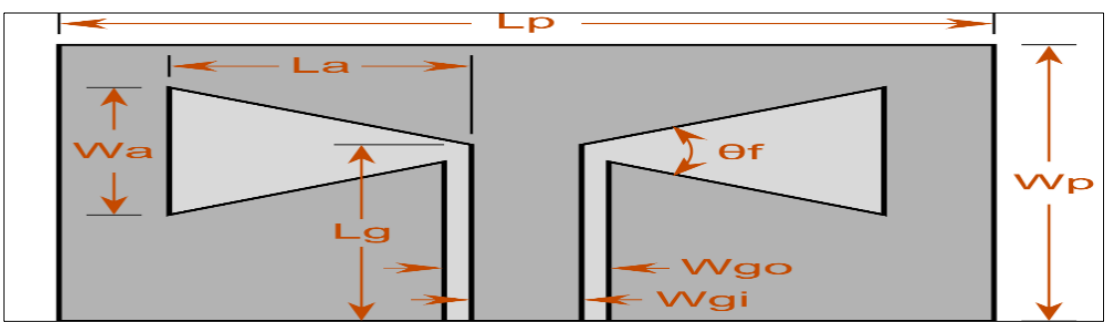

Figure 5 Design of the bow-tie antenna

Table 2 Optimised parameters for CPW fed bow-tie antenna design

\begin{tabular}{lcc}
\hline Parameters & Symbols & Values \\
\hline Arm length & $L_{a}$ & $72.10 \mathrm{~mm}$ \\
Arm width & $W_{a}$ & $42.50 \mathrm{~mm}$ \\
Feeding angle & $\Theta_{f}$ & $31.88^{\circ}$ \\
Length of CPW feed & $L_{g}$ & $133.00 \mathrm{~mm}$ \\
Inner width of the CPW feed line & $W_{g i}$ & $2.80 \mathrm{~mm}$ \\
Outer width of the CPW feed line & $W_{g o}$ & $3.80 \mathrm{~mm}$ \\
Width of the substrate, FR4 & $W_{p}$ & $170.00 \mathrm{~mm}$ \\
Length of the substrate, FR4 & ${ }^{2}{ }_{p}$ & $180.00 \mathrm{~mm}$ \\
Height of the substrate, FR4 & ${ }_{\mathrm{h}}$ & $1.6 \mathrm{~mm}$ \\
Height of the conductor, Cu layer & $t_{c}$ & $0.035 \mathrm{~mm}$ \\
Dielectric constant of the substrate & $\varepsilon_{r}$ & 4.3 \\
\hline
\end{tabular}




\subsection{Fabrication}

The Gerber files generated by CST Microwave Studio are used to fabricate both the antennas using an automated Computerized Numerical Control (CNC) prototyping machine A437. To fabricate the microstrip patch antenna, a commonly available $300 \mathrm{~mm} \times 300$ $\mathrm{mm}$ double sided FR4 copper clad board is placed on the bed of the prototyping machine. The machine removes the unnecessary copper from the board as specified in the Gerber file and cuts it to size 122.86 $\mathrm{mm} \times 91.3 \mathrm{~mm}$. The tool has a resolution of $1 \mu \mathrm{m}$. Figure 6 shows the fabricated microstrip patch antenna.

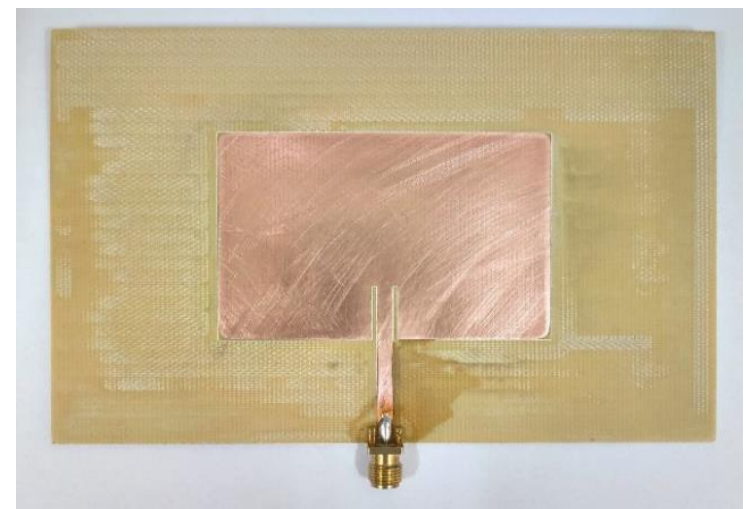

Figure 6 Picture of the fabricated microstrip patch antenna

To fabricate the bow-tie antenna, a similar process is undertaken, and the FR4 board is cut to a size of 180 $\mathrm{mm} \times 170 \mathrm{~mm}$. Figure 7 shows the fabricated bow-tie antenna.

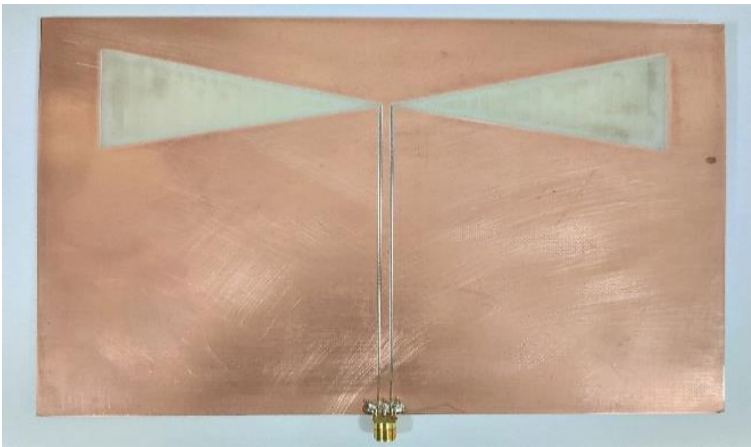

Figure 7 Picture of the fabricated Bow-tie Antenna

\section{Results}

The microstrip antenna is excited with $50 \quad \Omega$ waveguide port and simulated. The return loss and the Voltage Standing Wave Ratio (VSWR) of the fabricated antenna are measured with a VNA. Figures 8 and 9 show the simulated and the experimental return loss and the VSWR characteristics of the microstrip patch antenna. As seen from the figures, the simulated results closely resemble the measured results. The simulated bandwidth covers from 1.48 $\mathrm{GHz}$ to $1.52 \mathrm{GHz}(\sim 2.66 \%)$ at $\mathrm{S} 11=-10 \mathrm{~dB}$ level with the minimum return loss at $1.50 \mathrm{GHz}(-29.33 \mathrm{~dB})$. The measured bandwidth covers from $1.494 \mathrm{GHz}$ to 1.524 $\mathrm{GHz}(\sim 2 \%)$ with minimum return loss at $1.51 \mathrm{GHz}(-$ $30.53 \mathrm{~dB})$. The discrepancies in simulated and the measured results may be attributed to the SubMiniature Version A (SMA) connector, which is not considered during simulation, and the variation of dielectric properties of the substrate used to fabricate the antenna.

The bow-tie antenna is excited with $50 \Omega$ waveguide port and the simulation is carried out. The return loss and the VSWR of the fabricated antenna are measured using a VNA. Figures 10 and 11 show the simulated and experimental return loss and the VSWR characteristics of the bow-tie antenna.

As seen from the figures, the simulated bandwidth covers from $1.33 \mathrm{GHz}$ to $1.96 \mathrm{GHz}(42 \%)$ at $\mathrm{S} 11=-$ $10 \mathrm{~dB}$ level with the minimum return loss at 1.499 $\mathrm{GHz}(-36.99)$. The measured bandwidth covers from $1.26 \mathrm{GHz}$ to $2.24 \mathrm{GHz}(\sim 65.33 \%)$ with minimum return loss at $1.46 \mathrm{GHz}(-33.60)$. The discrepancies in simulated and measured results may be attributed to the SMA connector used, which is not considered during simulation, defects during fabrication of the CPW feed line and the variations of dielectric properties of the used to fabricate the antenna.

Figure 12 shows the simulated directivity and the gain patterns of the microstrip and bow-tie antennas in Eplane $\left(\mathrm{Phi}=0^{\circ}\right)$ and H-plane $\left(\mathrm{Phi}=90^{\circ}\right)$. Both the antennas show good directivity and gain in the endfire direction. However, it is seen that the bow-tie antenna has a narrower beam width and higher gain. Figures 13 and 14 show the simulated 3D radiation patterns of the microstrip and bow-tie antennas respectively. The microstrip antenna has a gain of $1.57 \mathrm{~dB}$ whereas the bow-tie antenna' gain is $7.02 \mathrm{~dB}$ at their centre frequencies. The higher gain of the bow-tie will definitely make it a better GPR antenna because the signal can propagate deeper into the ground. 


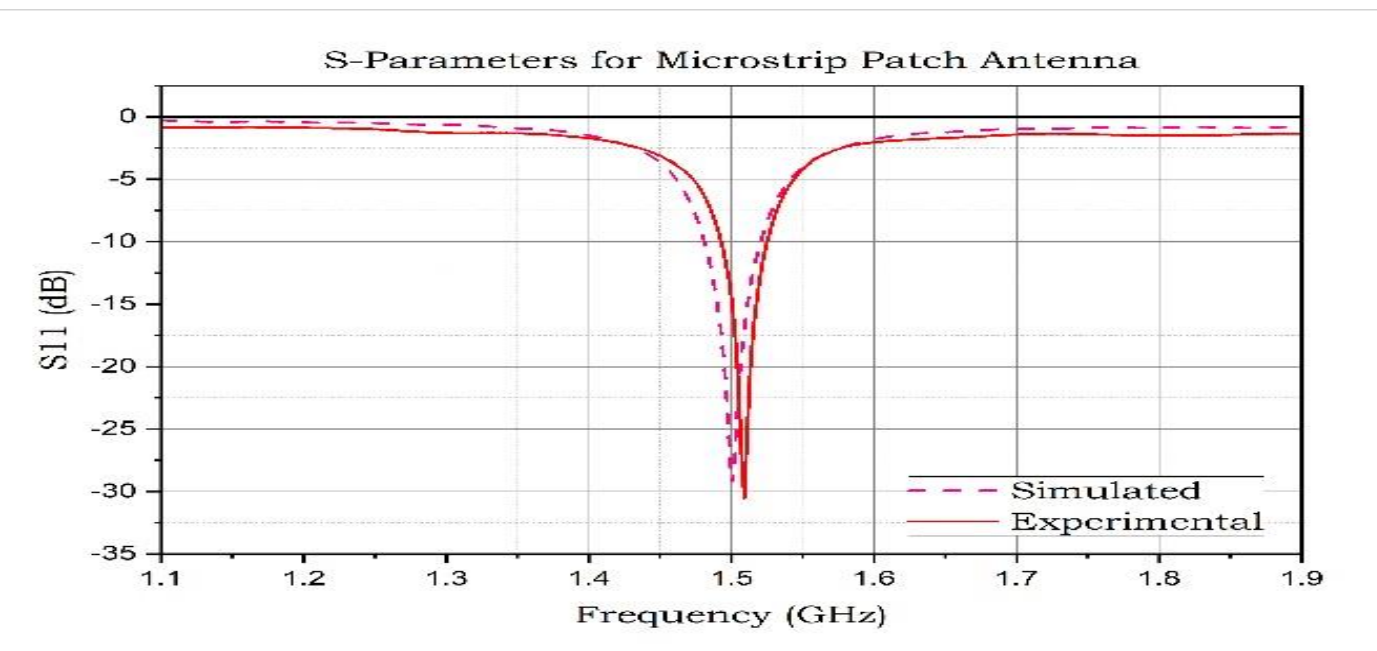

Figure 8 S-Parameters of microstrip patch antenna

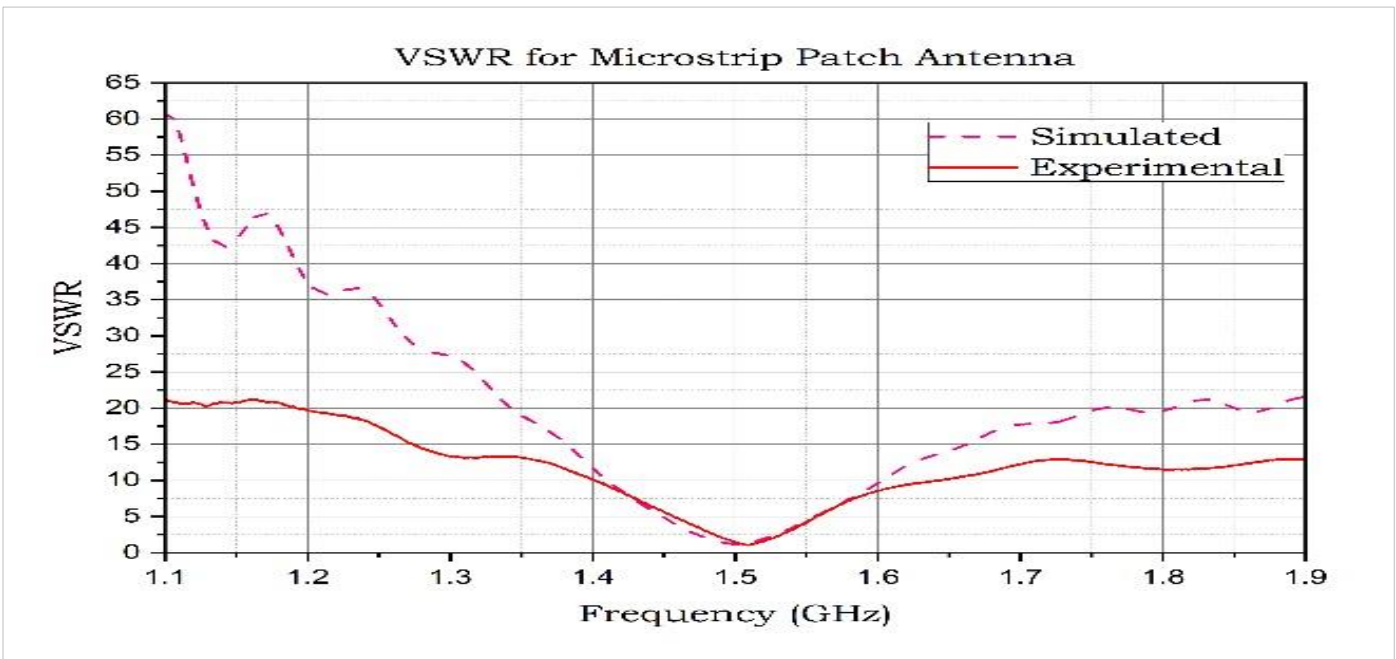

Figure 9 VSWR of microstrip patch antenna

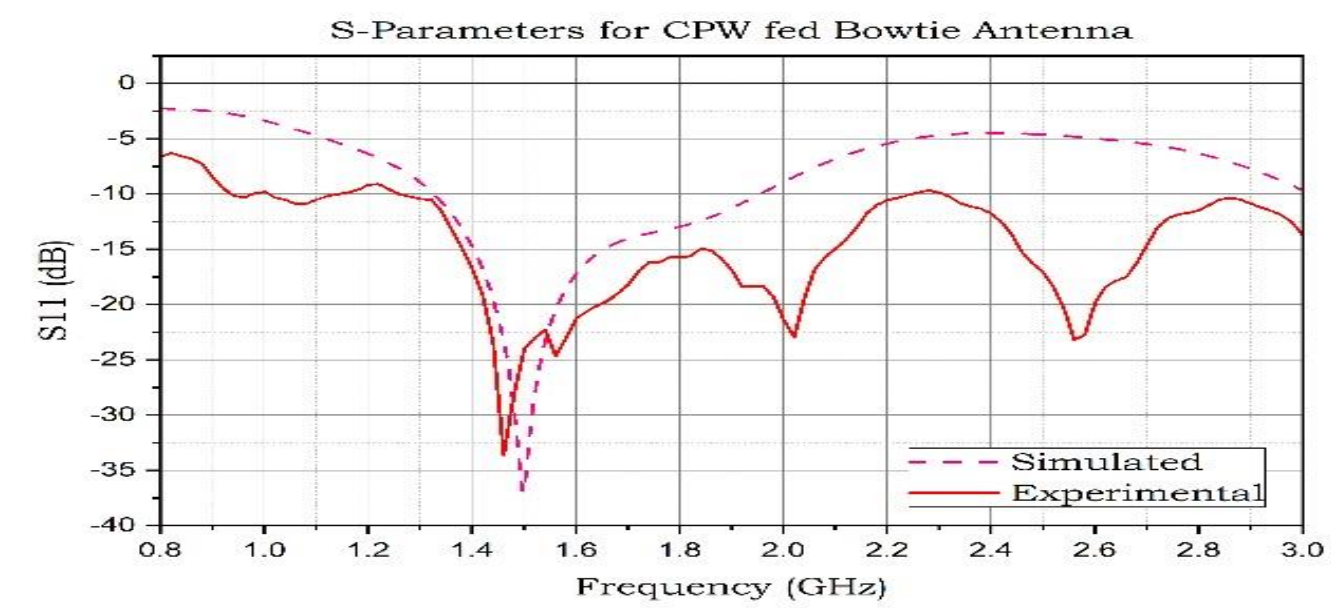

Figure 10 S-Parameters of bow-tie antenna 759 
Nairit Barkataki et al.

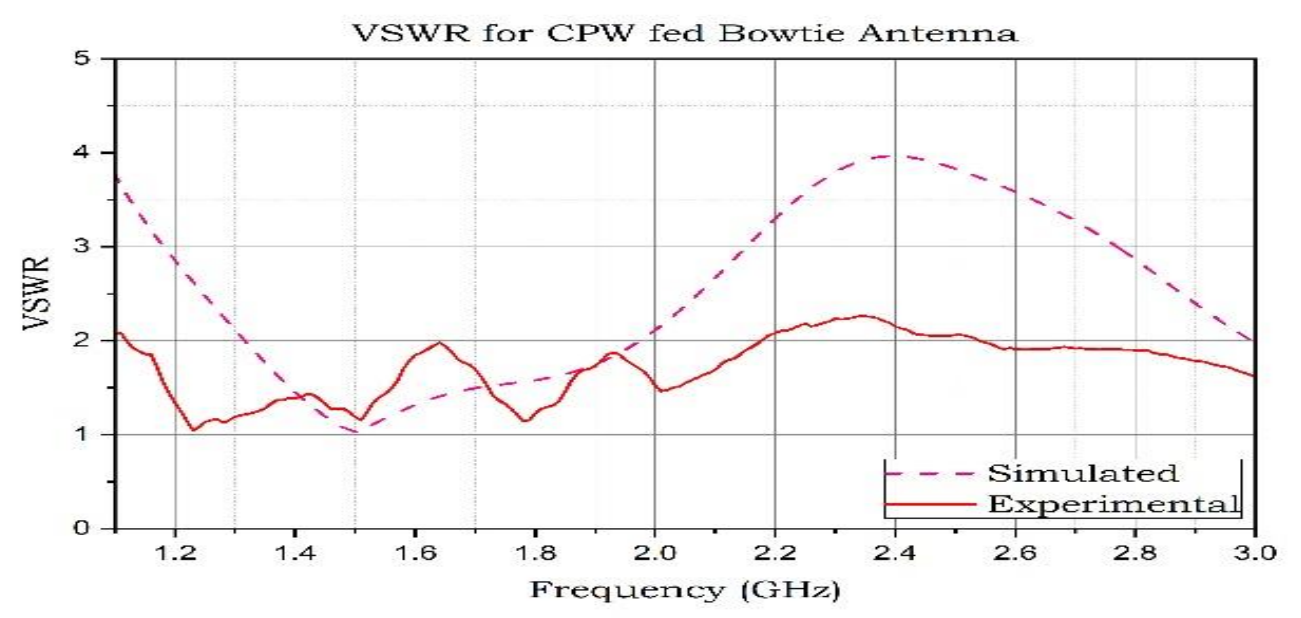

Figure 11 VSWR of bow-tie antenna
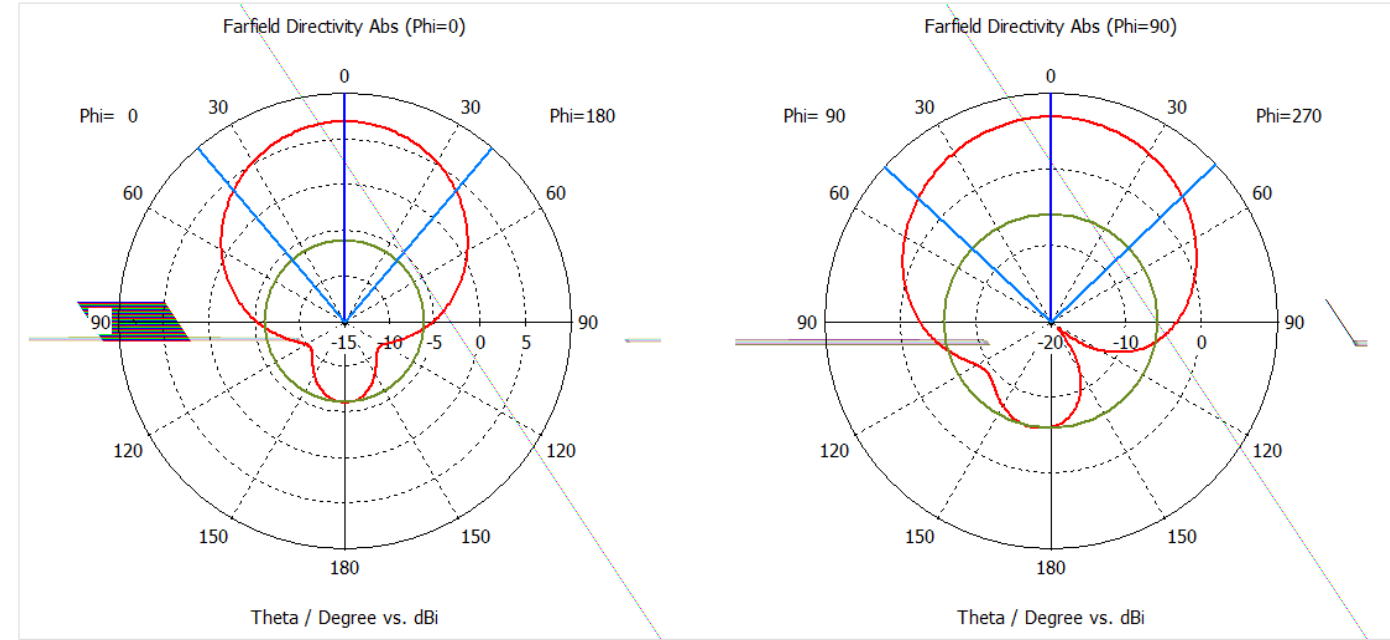

(a) Simulated directivity patterns for microstrip patch antenna

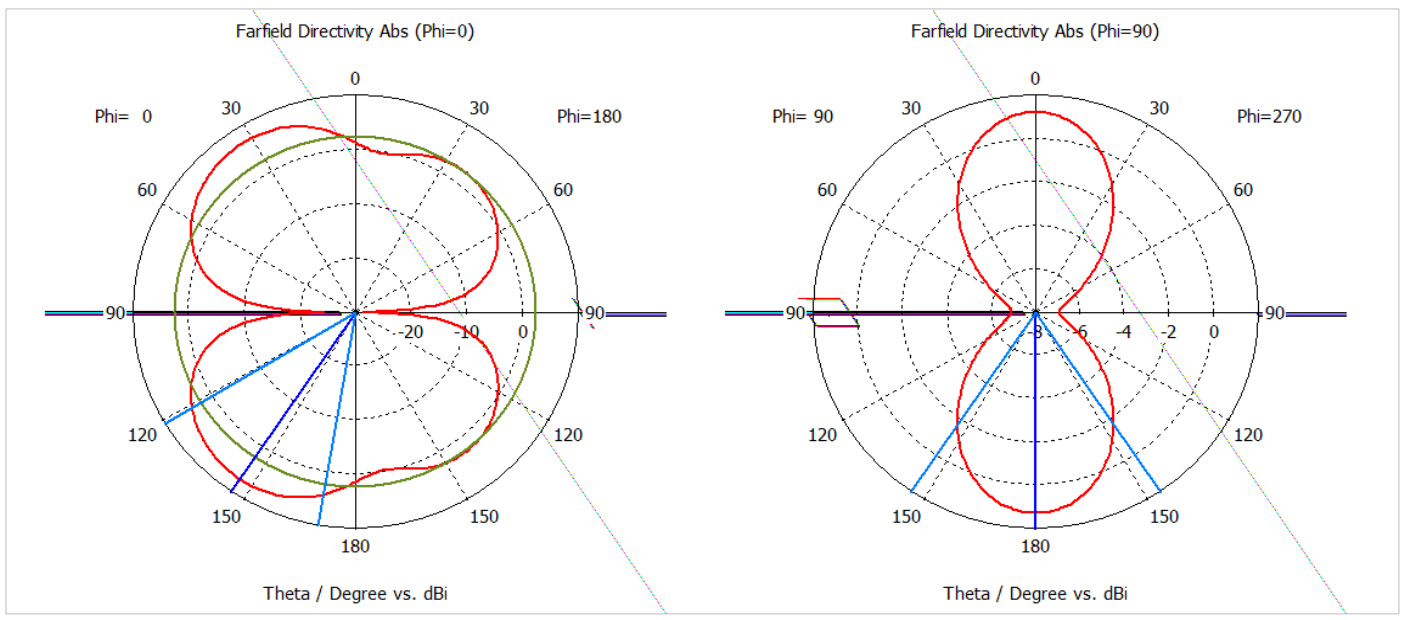

(b) Simulated directivity patterns for bow-tie antenna 
International Journal of Advanced Technology and Engineering Exploration, Vol 8(79)

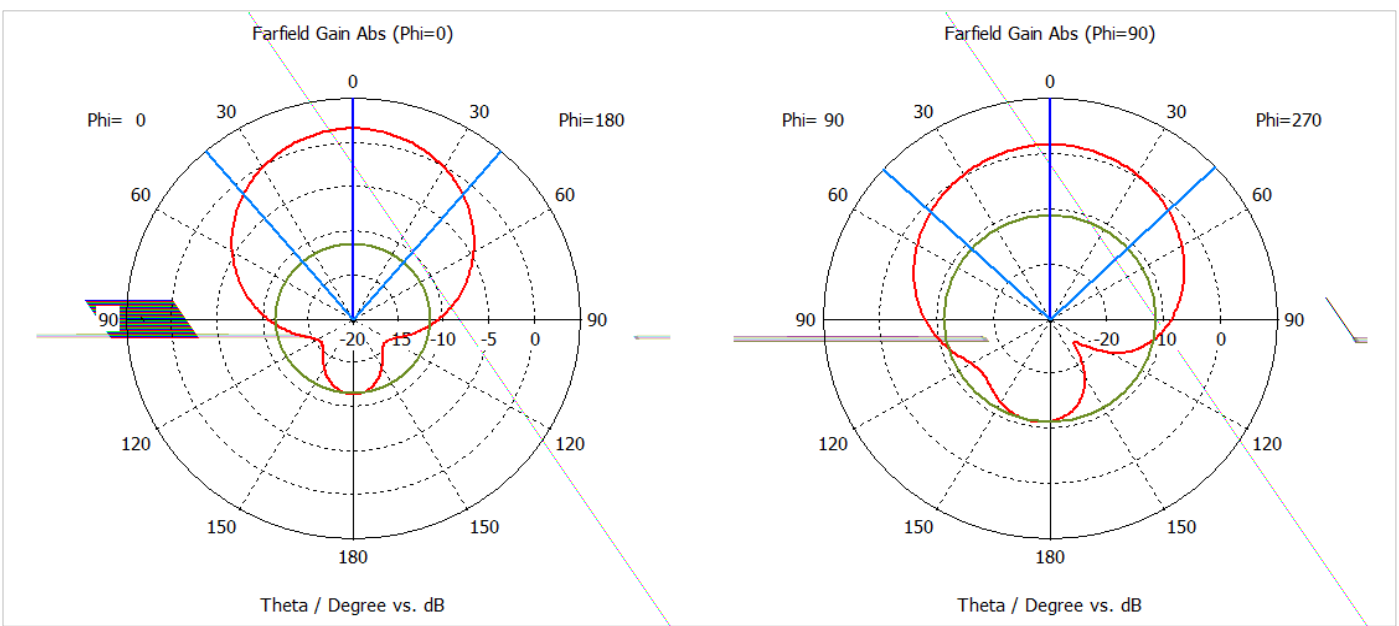

(c) Simulated radiation patterns for microstrip patch antenna

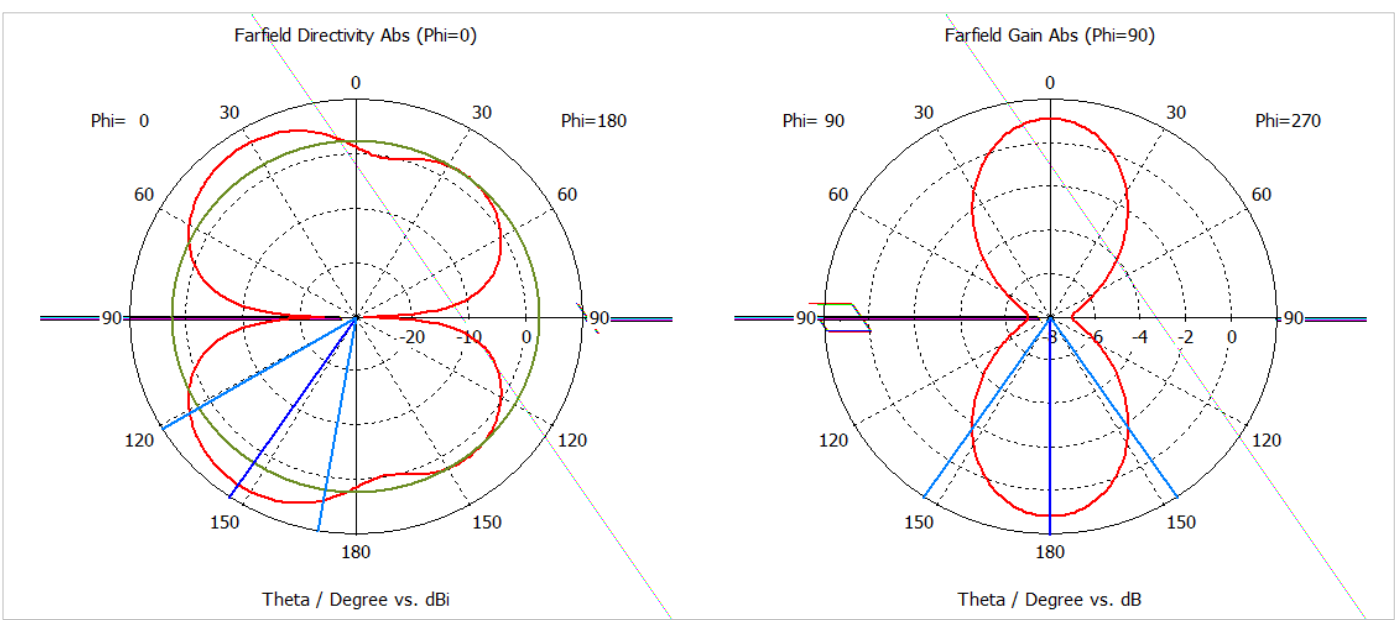

(d) Simulated gain patterns for bow-tie antenna

Figure 12 Simulated directivity and gain patterns for both antennas

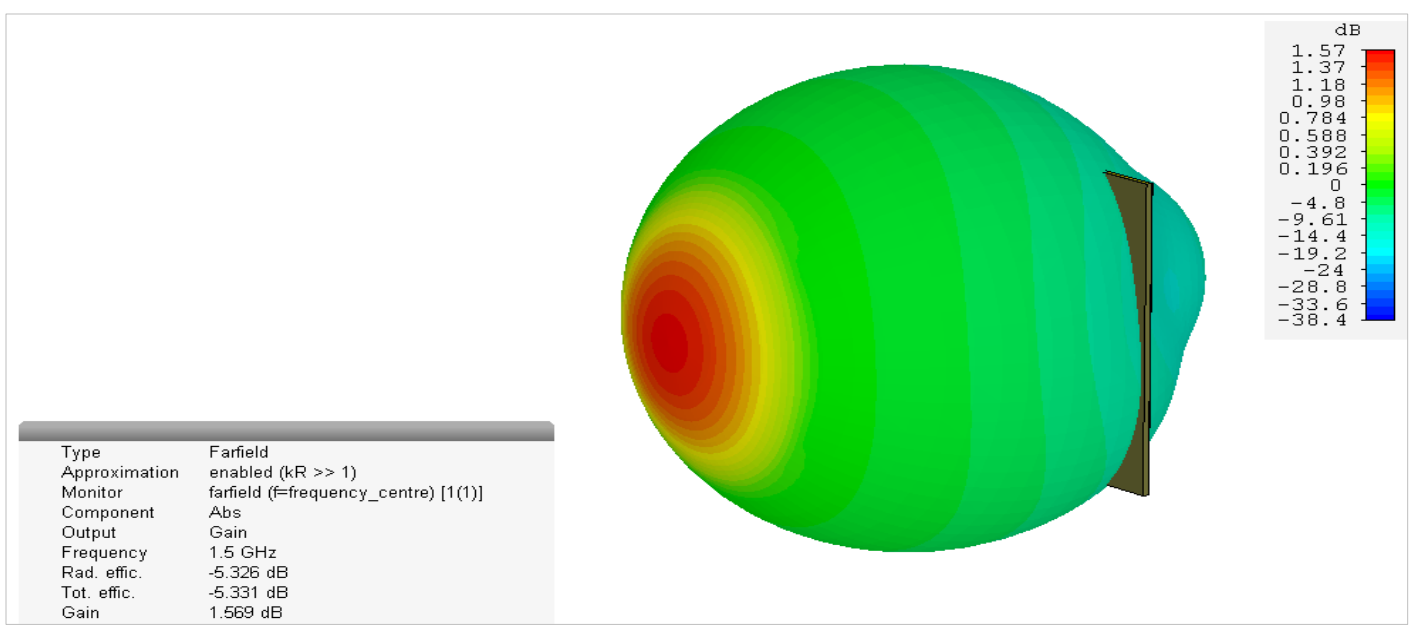

Figure 13 3D Radiation pattern of microstrip patch antenna 


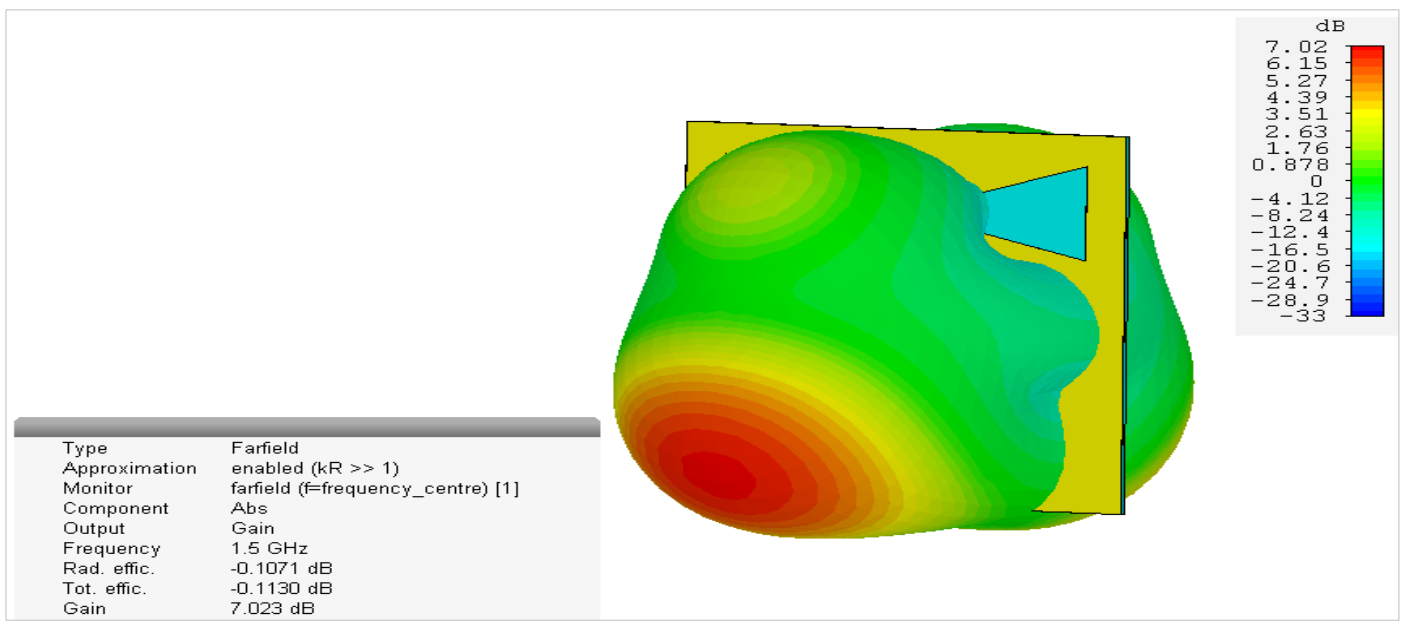

Figure 14 3D Radiation pattern of Bow-tie Antenna

\section{Discussion}

It is seen that the bow-tie antenna has better directivity and much higher gain in the endfire direction, compared to the microstrip planar antenna. It is also seen that the antenna shows resonance at $1.56 \mathrm{GHz}(-$ $24.67 \mathrm{~dB}), 2.02 \mathrm{GHz}(-22.95 \mathrm{~dB})$ and $2.56 \mathrm{GHz}(-$ $23.19 \mathrm{~dB})$. These may be attributed to the capacitive effect due to the coplanar waveguide feeding. The measured results show a better bandwidth $(\sim 65.33 \%)$ than the simulated results $(42 \%)$. The bow-tie antenna has better bandwidth than the microstrip antenna for the same central frequency of $1.5 \mathrm{GHz}$.

\subsection{Comparison}

Table 3 compares the performance of the bow-tie antenna with other UWB antennas as reported in literature. The proposed antenna is simple to fabricate, low cost while preserving good directivity and high gain. Moreover, it is smaller in size than the other antennas.

Table 3 Comparison of antenna performance

\begin{tabular}{|c|c|c|c|}
\hline Reference & Structure & \multicolumn{2}{|c|}{ FrequencyMax Gain (dB)Complexity/ease } \\
\hline \multicolumn{2}{|c|}{ Richardson et al. [32]Cavity backed spiral (3D) } & $0.75-1.25 \quad 6$ & Complex \\
\hline Guo et al. [34] & Vivaldi with exponential tapered slots (planar) & $0.3-2$ & Simple but Large Size \\
\hline Liu et al. [41] & Cavity backed bow-tie with dielectric loading (3D) & $1-4$ & Complex \\
\hline Li and Chen [42] & Slotted bow-tie with artificial magnetic conductor $(\mathrm{p}$ & $0.56-1.18-$ & Complex \\
\hline Proposed antenna & CPW fed bow-tie (planar) & $1.26-2.24 \quad 7$ & Simple and Low Cost \\
\hline
\end{tabular}

\subsection{Limitations}

The GPR waveform is usually a short pulse with a very large instantaneous bandwidth. Such short pulses are generated by imposing a step function voltage onto an antenna, which creates a ringing effect (oscillations) for normal antennas. When this effect is strong, deeper targets of interest in a GPR survey may be completely masked. By applying resistive loading to the antenna, this effect can be reduced. As seen in Figures 12 (b) and (d), the directivity and the gain patterns of the bow-tie antenna extend to both front and back sides of the antenna. This affects its Front-To-Back (F/B) ratio.

Complete list of abbreviations is shown in Appendix I.

\section{Conclusion and future work}

In this paper, the simulated and the measured results of a planar microstrip antenna and a bow-tie slot antenna are discussed. The use of UWB signal source in GPR is well known. The main advantage of using a UWB signal is the need for better vertical resolution (depth resolution). The antennas are first designed and simulated using CST Microwave Studio. Later, the fabricated antennas are tested using a Rohde \& Schwarz ZNB20 VNA. The measured bandwidth of the bow-tie antenna is $\sim 65.33 \%(1.26 \mathrm{GHz}$ to 2.24 $\mathrm{GHz}$ ) as compared to the microstrip antenna's bandwidth of $\sim 2 \%(1.494 \mathrm{GHz}$ to $1.524 \mathrm{GHz})$. The microstrip antenna has a maximum gain of $1.57 \mathrm{~dB}$ whereas the bow-tie antenna has a maximum gain of $7.02 \mathrm{~dB}$. The high bandwidth and gain of the bow-tie 
antenna makes it a better GPR antenna with deep penetration and better resolution imaging. Its planar structure, low form factor and lightweight design make the bow-tie antenna easy to be integrated within the enclosure containing other GPR equipments, as compared to other antenna types such as the horn antenna and the spiral antenna. The CPW feeding mechanism makes the bow-tie antenna suitable for integration with PCB circuitry. The authors plan to further improve the existing design by reducing the ringing effect. The directivity, gain and the $\mathrm{F} / \mathrm{B}$ ratio of the bow-tie antenna can be further improved if a planar reflector is used.

\section{Acknowledgment}

The authors would like to thank the editor and reviewers whose comments and suggestions helped increase the quality of the manuscript. The authors would also like to thank Dr. Shakeel Zamal for his insightful suggestions.

\section{Conflicts of interest}

The authors have no conflicts of interest to declare.

\section{References}

[1] Chang CW, Lin CH, Yuan QW. Quantitative study of electromagnetic wave characteristic values for mortar's crack. Construction and Building Materials. 2018; 175:351-9.

[2] Zajícová K, Chuman T. Application of ground penetrating radar methods in soil studies: a review. Geoderma. 2019; 343:116-29.

[3] Benedetto A, Benedetto F, Tosti F. GPR applications for geotechnical stability of transportation infrastructures. Nondestructive Testing and Evaluation. 2012; 27(3):253-62.

[4] Diallo MC, Cheng LZ, Rosa E, Gunther C, Chouteau M. Integrated GPR and ERT data interpretation for bedrock identification at Cléricy, Québec, Canada. Engineering Geology. 2019; 248:230-41.

[5] Alsharahi G, Faize A, Louzazni M, Mostapha AM, Bayjja M, Driouach A. Detection of cavities and fragile areas by numerical methods and GPR application. Journal of Applied Geophysics. 2019; 164:225-36.

[6] Borden KA, Isaac ME, Thevathasan NV, Gordon AM, Thomas SC. Estimating coarse root biomass with ground penetrating radar in a tree-based intercropping system. Agroforestry Systems. 2014; 88:657-69.

[7] Jol HM. Ground penetrating radar theory and applications. Elsevier; 2008.

[8] Daniels DJ. Ground penetrating radar. Encyclopedia of RF and Microwave Engineering. 2005. John Wiley \& Sons

[9] Ávila-navarro E, Carrasco JA, Reig C. Printed dipole antennas for personal communication systems. IETE Technical Review. 2010; 27(4):286-92.

[10] Turk AS, Sahinkaya DA, Sezgin M, Nazli H. Investigation of convenient antenna designs for ultrawide band GPR systems. In international workshop on, advanced ground penetrating radar 2007 (pp. 192-6). IEEE.

[11] Hertl I, Strycek M. UWB antennas for ground penetrating radar application. In 19th international conference on applied electromagnetics and communications 2007 (pp. 1-4). IEEE.

[12] Cheng H, Yang H, Li Y, Chen Y. A compact vivaldi antenna with artificial material lens and sidelobe suppressor for GPR applications. IEEE Access. 2020; 8:64056-63.

[13] Jamali AA, Marklein R. Design and optimization of ultra-wideband TEM horn antennas for GPR applications. In URSI general assembly and scientific symposium 2011 (pp. 1-4). IEEE.

[14] Mohamed HA, Elsadek H, Abdallah EA. Quad ridged UWB TEM horn antenna for GPR applications. In radar conference 2014 (pp. 79-82). IEEE.

[15] Wang J, Su Y, Huang C, Lu M, Li Y. Design of bowtie antenna with high radiating efficiency for impulse GPR. In international geoscience and remote sensing symposium 2012 (pp. 594-7). IEEE.

[16] Ajith KK, Bhattacharya A. Improved ultra-wide bandwidth bow-tie antenna with metamaterial lens for GPR applications. In proceedings of the international conference on ground penetrating radar 2014 (pp. 73944). IEEE.

[17] Nayak R, Maiti S, Patra SK. Design and simulation of compact UWB Bow-tie antenna with reduced end-fire reflections for GPR applications. In international conference on wireless communications, signal processing and networking 2016 (pp. 1786-90). IEEE.

[18] Lu W, Li Y, Ji Y, Shen S, Tang C, Zhou B, et al. High reliability UWB monopole antenna using planar embedded resistance for mars subsurface exploration. Electronics. 2021; 10(6):1-13.

[19] Alam AZ, Islam MR, Khan S. Design and analysis of UWB rectangular patch antenna. In asia-pacific conference on applied electromagnetics 2007 (pp. 1-3). IEEE.

[20] Karim MN, Malek MF, Jamlos MF, Saudin N. Ground penetrating radar: antenna for buried object detection. In symposium on wireless technology \& applications 2013 (pp. 198-201). IEEE.

[21] Jung J, Choi W, Choi J. A small wideband microstripfed monopole antenna. IEEE Microwave and Wireless Components Letters. 2005; 15(10):703-5.

[22] Wong $\mathrm{KL}, \mathrm{Wu} \mathrm{CH}$, Su SW. Ultrawide-band square planar metal-plate monopole antenna with a tridentshaped feeding strip. IEEE Transactions on Antennas and Propagation. 2005; 53(4):1262-9.

[23] Yang T, Davis WA. Planar half-disk antenna structures for ultra-wideband communications. In antennas and propagation society symposium 2004 (pp. 2508-11). IEEE.

[24] Lee SH, Park JK, Lee JN. A novel CPW-fed ultrawideband antenna design. Microwave and Optical Technology Letters. 2005; 44(5):393-6.

[25] Chen ZN, Chia MY, Ammann MJ. Optimization and comparison of broadband monopoles. IEE 
Nairit Barkataki et al.

Proceedings-Microwaves, Antennas and Propagation. 2003; 150(6):429-35.

[26] Su SW, Wong KL, Tang CL. Ultra-wideband square planar monopole antenna for IEEE 802.16 a operation in the $2-11-\mathrm{GHz}$ band. Microwave and Optical Technology Letters. 2004; 42(6):463-6.

[27] Alsath MG, Kanagasabai M. Compact UWB monopole antenna for automotive communications. IEEE Transactions on Antennas and Propagation. 2015; 63(9):4204-8.

[28] Jain P, Singh B, Yadav S, Verma A. A semicircular monopole antenna for ultra-wideband applications. In proceedings of international conference on ICT for sustainable development 2016 (pp. 339-45). Springer, Singapore.

[29] Keshwala U, Rawat S, Ray K. Compact half-hexagonal monopole planar antenna for UWB applications. In soft computing: theories and applications 2018 (pp. 22531). Springer, Singapore.

[30] Ling CW, Chung SJ. A simple printed ultrawideband antenna with a quasi-transmission line section. IEEE Transactions on Antennas and Propagation. 2009; 57(10):3333-6.

[31] Thomas KG, Sreenivasan M. A simple ultrawideband planar rectangular printed antenna with band dispensation. IEEE Transactions on Antennas and Propagation. 2009; 58(1):27-34.

[32] Richardson M, Bauder CJ, Kazemi R, Fathy AE. Design of a rigid UWB log spiral antenna for GPR applications in harsh environment. In radio and wireless symposium (RWS) 2020 (pp. 262-4). IEEE.

[33] Bousbaa W, Medkour H, Bouttout F, Messali Z. Fully planar frequency independent square archimedean spiral antenna with impedance transformer for ground penetrating radars. Microwave and Optical Technology Letters. 2021; 63(1):295-309.

[34] Guo J, Tong J, Zhao Q, Jiao J, Huo J, Ma C. An ultrawide band antipodal Vivaldi antenna for airborne GPR application. IEEE Geoscience and Remote Sensing Letters. 2019; 16(10):1560-4.

[35] Srivastav A, Nguyen P, McConnell M, Loparo KA, Mandal S. A highly digital multiantenna groundpenetrating radar (GPR) system. IEEE Transactions on Instrumentation and Measurement. 2020; 69(10):742236.

[36] Raza A, Lin W, Chen Y, Yanting Z, Chattha HT, Sharif $\mathrm{AB}$. Wideband tapered slot antenna for applications in ground penetrating radar. Microwave and Optical Technology Letters. 2020; 62(7):2562-8.

[37] Kundu S, Chatterjee A, Iqbal A. Printed circular ultrawideband antenna with triple sharp frequency notches for surface penetrating radar application. Sādhanā. 2020; 45:1-7.

[38] Rahim MK, Aziz MA, Goh CS. Bow-tie microstrip antenna design. In IEEE international conference on networks jointly held with the IEEE Malaysia international conf on communic 2005. IEEE.

[39] Chen G, Liu RC. A 900MHz shielded bow-tie antenna system for ground penetrating radar. In proceedings of

the international conference on ground penetrating radar 2010 (pp. 1-6). IEEE.

[40] Takizawa H, Matsubayashi K, Michishita N, Morishita H, Kawabata K. Study on impedance matching and miniaturization of bow-tie antenna with folded structure and slit for ground penetrating radar. In international workshop on antenna technology 2020 (pp. 1-2). IEEE.

[41] Liu S, Li M, Li H, Yang L, Shi X. Cavity-backed bowtie antenna with dielectric loading for groundpenetrating radar application. IET Microwaves, Antennas \& Propagation. 2019; 14(2):153-7.

[42] Li Y, Chen J. Improved high gain miniaturized bow-tie antenna with AMC. In MTT-S international conference on numerical electromagnetic and multiphysics modeling and optimization (NEMO) 2020 (pp. 1-4). IEEE.

[43] Chen S, Jia W, Lin J, Zhang Y. Research and design of tripod-shaped UWB antenna for GPR. In IOP conference series: earth and environmental science 2021 (pp. 1-7). IOP Publishing.

[44] Nayak R, Maiti S. A review of bow-tie antennas for GPR applications. IETE Technical Review. 2018; 36(4):382-97.

[45] Garg R, Bhartia P, Bahl IJ, Ittipiboon A. Microstrip antenna design handbook. Artech House; 2001.

[46] Shakib MN, Moghavvemi M, Mahadi WN. Design of a compact planar antenna for ultra-wideband operation. Applied Computational Electromagnetics Society Journal. 2015; 30(2):222-9.

[47] Visser HJ. Antenna theory and applications. John Wiley \& Sons; 2012.

[48] Karim MN, Malek MF, Jamlos MF, Abdullah AZ, Noorpi NM, Mokhtar NM, et al. CPW circular patch antenna for ground penetrating radar applications. In theory and applications of applied electromagnetics 2015 (pp. 59-67). Springer, Cham.

[49] Varkiani SM, Afsahi M. Compact and ultra-wideband CPW-fed square slot antenna for wearable applications. AEU-International Journal of Electronics and Communications. 2019; 106:108-15.

[50] Elsheakh DM, Abdallah EA. Novel shapes of vivaldi antenna for ground pentrating radar (GPR). In European conference on antennas and propagation (EuCAP) 2013 (pp. 2886-9). IEEE.

[51] Ghione G, Naldi C. Analytical formulas for coplanar lines in hybrid and monolithic MICs. Electronics Letters. 1984; 20(4):179-81.

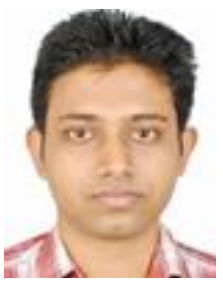

Processing. Email: nairitb@gauhati.ac.in
Nairit Barkataki received his M.Sc. degree from Gauhati University. Currently he is an Assistant Professor at Gauhati University. His research interests are Artificial Intelligence in Instrumentation (Deep Learning on FPGAs and GPUs), Instrumentation for Sericulture and Radar Signal 


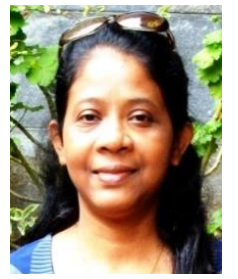

Communication.

Dr. Banty Tiru received her $\mathrm{PhD}$ degree from Gauhati University. She is currently an Associate Professor in the Department of Physics, Gauhati University. She has numerous publications in the field of Power Line Communication, Cosmic rays, Digital Signal Processing and Visible Light

Email: btiru@gauhati.ac.in

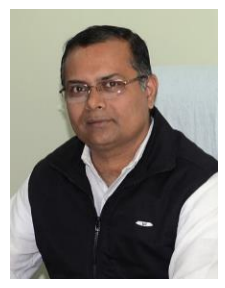

Utpal Sarma received his Ph.D. degree from Gauhati University, Guwahati, India, in 2010. He is currently a Professor in the Department of Instrumentation \& USIC, Gauhati University. His current research interests include Smart Sensors and Embedded System Design, Instrumentation for Agro Industries, MEMS for Energy Harvesting and Ground Penetrating Radar Signal Processing.

Email: utpalsarma@gauhati.ac.in

\section{Appendix I}

\begin{tabular}{lll}
\hline S.No. & Abbreviation & Description \\
\hline 1 & CNC & Computerized Numerical Control \\
\hline 2 & CPW & Coplanar Waveguide \\
\hline 3 & (F/B) ratio & Front-To-Back Ratio \\
\hline 4 & FR4 & Flame Retardant 4 \\
\hline 5 & GPR & Ground penetrating radar \\
\hline 6 & MPL & Microstrip line \\
\hline 7 & PCB & Printed circuit board \\
\hline 8 & SMA & SubMiniature version A \\
\hline 9 & TEM & Transverse electromagnetic \\
\hline 10 & UWB & Ultra-wideband \\
\hline 12 & VHF & Very high frequency \\
\hline 13 & VNA & Vector Network Analyser \\
\hline
\end{tabular}

